\title{
FROM SURVEY TO FEM ANALYSIS FOR DOCUMENTATION OF BUILT HERITAGE: THE CASE STUDY OF VILLA REVEDIN-BOLASCO
}

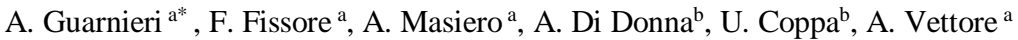 \\ ${ }^{a}$ CIRGEO, Interdepartment Research Center of Geomatics, University of Padua, Viale dell'Università 16, Legnaro (PD) 35020, Italy \\ (alberto.guarnieri, cirgeo) @unipd.it \\ ${ }^{\text {b} V e s u v i u s ~ O b s e r v a t o r y ~-~ N a t i o n a l ~ I n s t i t u t e ~ o f ~ G e o p h y s i c s ~ a n d ~ V o l c a n o l o g y ~-~ N a p l e s, ~ I t a l y, ~ c o p p a @ o v . i n g v . i t, ~ a . d i d o n n a @ h o t m a i l . i t ~}$
}

KEY WORDS: Terrestrial Laser Scanning, 3D Modeling, Solid Modeling, Cultural Heritage, Finite Element Analysis

\begin{abstract}
In the last decade advances in the fields of close-range photogrammetry, terrestrial laser scanning (TLS) and computer vision (CV) have enabled to collect different kind of information about a Cultural Heritage objects and to carry out highly accurate 3D models. Additionally, the integration between laser scanning technology and Finite Element Analysis (FEA) is gaining particular interest in recent years for structural analysis of built heritage, since the increasing computational capabilities allow to manipulate large datasets. In this note we illustrate the approach adopted for surveying, 3D modeling and structural analysis of Villa Revedin-Bolasco, a magnificent historical building located in the small walled town of Castelfranco Veneto, in northern Italy. In 2012 CIRGEO was charged by the University of Padova to carry out a survey of the Villa and Park, as preliminary step for subsequent restoration works. The inner geometry of the Villa was captured with two Leica Disto D3a BT hand-held laser meters, while the outer walls of the building were surveyed with a Leica C10 and a Faro Focus 3D 120 terrestrial laser scanners. Ancillary GNSS measurements were also collected for 3D laser model georeferencing. A solid model was then generated from the laser global point cloud in Rhinoceros software, and portion of it was used for simulation in a Finite Element Analysis (FEA). In the paper we discuss in detail all the steps and challenges addressed and solutions adopted concerning the survey, solid modeling and FEA from laser scanning data of the historical complex of Villa Revedin-Bolasco.
\end{abstract}

\section{INTRODUCTION}

In the last decade improvements in surveying techniques (e.g. Terrestrial Laser Scanning-TLS, close range photogrammetry) and in digital data processing and management have allowed to collect different kind of information about a Cultural Heritge object. Whether it is a simple statue, a small artifact, a fragment or a whole ancient building or archeological site, current digital technology provides the users (scholars, professionals or wider audience) many instruments to analyze, study and explore the historical good. For example, through the generation of multiresolution digital 3D models, geometrical, spatial, radiometric and multispectral contents of investigated objects can be captured and stored in digital form for documentation and conservation purposes. Three-dimensional modelling and representation through laser scanner surveys is a widely used method in the field of architecture and cultural heritage. It is well known that TLS technique not only provides information about the geometry of the object of interest, but also it enables to extrapolate information abut the state of conservation directly in a 3D environment. Moreover, in last years the integration between laser scanning technology and photogrammetry has also proven to be a very effective methodology to provide high-resolution 3D models of heritage sites and cultural artifacts. Through this approach, the geometry and appearance of real objects can be recorded with high level of detail and accuracy. Several works published so far have demonstrated how Cultural Heritage $(\mathrm{CH})$ can greatly benefit from 3D modeling applied to object or historical/ archaeological site analysis, documentation, preservation and restoration (Barber et al., 2001; Guarnieri et al., 2004; Beraldin et al., 2005; Remondino et al., 2008). For instance, working in a 3D environment allows to digitally remove unwanted elements from the model and to view the object/site in his correct historical context. Virtual restoration can be used to improve the knowledge of a site without resorting to interventions often traumatic for the original artifact. Furthermore, $\mathrm{CH}$ can also benefit from the use of Virtual Reality (VR) and its integration with Hypermedia and Computer Graphics (CG). The advantages of using these technologies include the virtual reconstruction of buildings, sites or objects that no longer or only partially exist, the simulation of viewpoints not available in the real world, the direct interaction with virtual reproductions of artifacts, thus eliminating the risk of degradation. Virtual Reality environments created around such 3D models represent very often an easy way to give accessibility to $\mathrm{CH}$ among a wide variety of users.

3D visualisation and proper documentation of cultural objects helps to preserve the history and memories of historic buildings, archaeological sites and cultural landscapes, and supports economic growth by stimulating cultural tourism. Additionally, the integration between laser scanning technology and Finite Element Analysis (FEA) is gaining particular interest in recent years for structural analysis of built heritage, since the increasing computational capabilities allow to manipulate large datasets. FEA is an exciting engineering solution that digitally predicts and simulates material behavior under defined conditions. Using build material information and accurate 3D models of a part or assembly, FEA enables predicting structural or performance problems before they occur in the real world.

In this note we illustrate the approach adopted for surveying, 3D modeling and structural analysis of the magnificent historical building of Villa Revedin-Bolasco. The work has been undertaken within the framework of a restoration project promoted by the University of Padova, in conjunction with the municipality of Castelfranco, and supported by the Regione Veneto through european funds. 


\section{THE STUDY SITE: VILLA REVEDIN BOLASCO}

The building of Villa Revedin-Bolasco is only a few minutes walk away from the centre of Castelfranco Veneto, a small ancient walled town located in the province of Treviso, in northern Italy (Figure 1). The building comprises a venetianstyle villa and a park extending over an area of 7.63 hectares (Figures 2 and 3). The Villa, originally built in 1400 by Tempesta noble family, has undergone over the centuries several tranfers of ownership and transformations which significantly changed its original structure. The current overall appearance of the Villa is due to the design of architect Giambattista Meduna - famous for the drawings of the La Fenice Theater in Venice - which completely rebuilt the structure between 1852 and 1865 under commitment of Count Francesco Revedin. With 160 rooms arranged on three floors, the Villa develops around two courtyards: the owner one in the south side, while the second one hosting farmer activities and other services dedicated to the mantainance of the complex lies in the north side. Located inside the Villa, the dance-hall painted by Giacomo Casa and the stylish stables are of remarkable artistic interest (Figures 4 and 5).

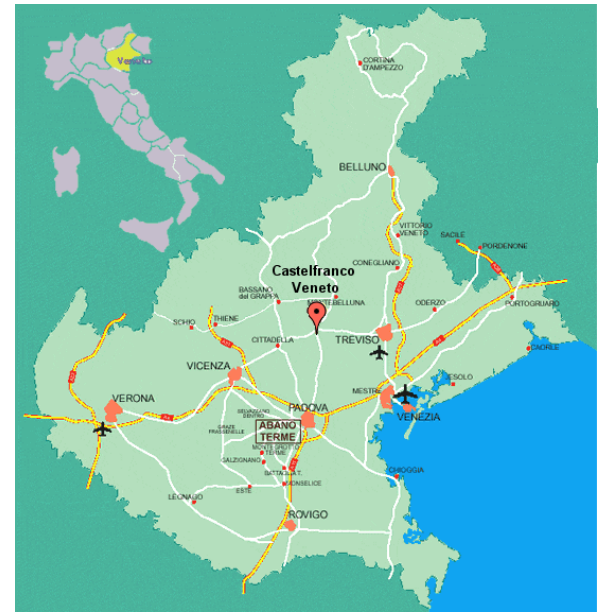

Figure 1: Geographic location of Castelfranco Veneto, Italy

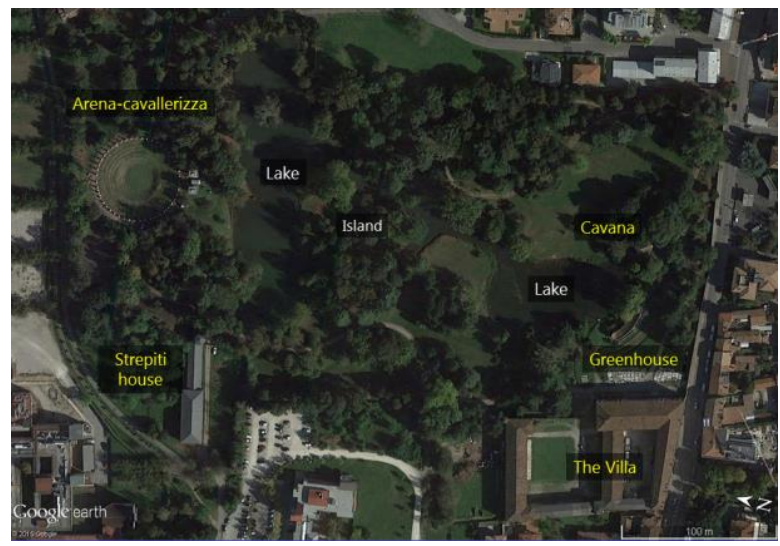

Figure 2: Aerial view of Villa Revedin-Bolasco and the Park

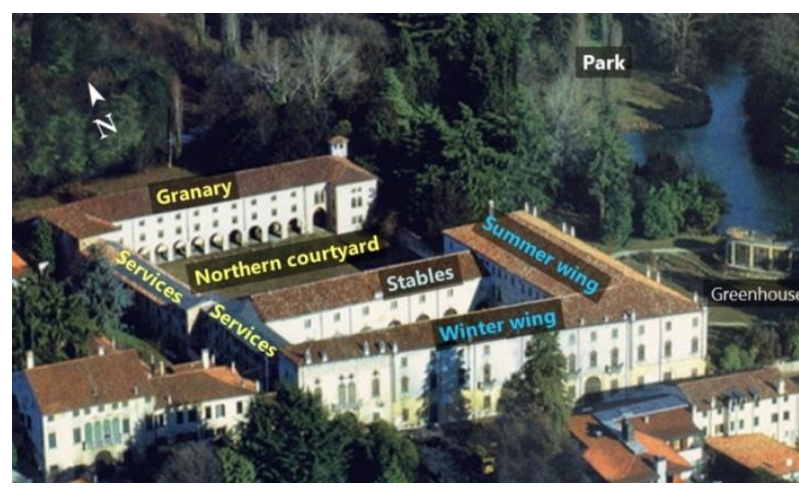

Figure 3: Perspective view of Villa Revedin-Bolasco

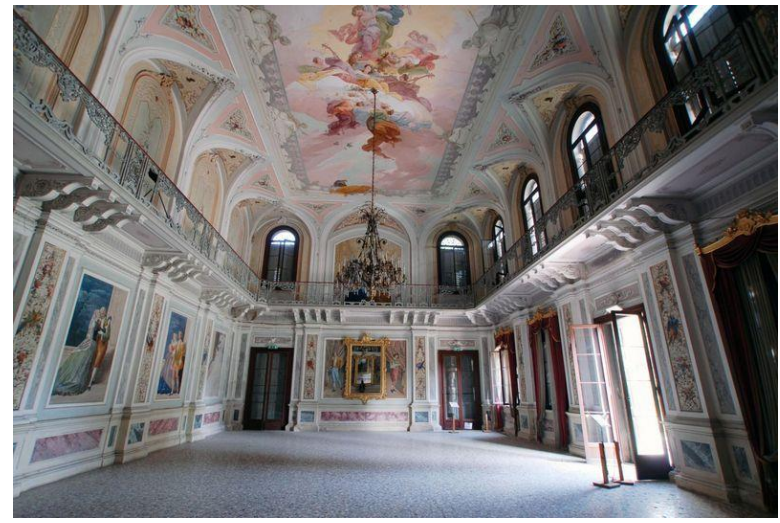

Figure 4: The dance-hall painted by Giacomo Casa

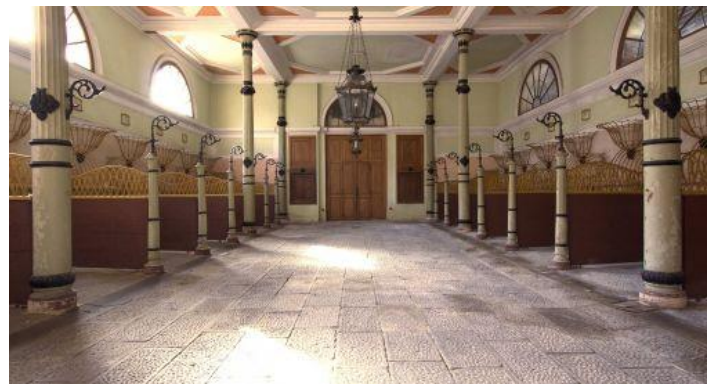

Figure 5: The stables.

In place of the italian-style garden, the "Paradise", created by previous noble venetian Cornèr family, Count Francesco Revedin also let set up a Romantic English graden, known as the Revedin-Bolasco Park. It was designed by Meduna and other famous landscape designers of the time, including Francesco Bagnara and Marc Guignon from France. A walk in the Park reveals enchanting views dappled with rays of light, everchanging shades and colours, trees and ponds, meadows and thickets, small bridgesand man-made hillocks. Buildings are dotted here and there: the Hispanic-Moresque style greenhouse, a "cavana" (hut), a dovecot tower, and lastly, to the north, a true masterpiece, the so-called "arena-cavallerizza" (Figure 6). This is a riding ground featuring dozens of statues from the 17th century by Orazio Marinali from Bassano and two equestrian statues on high plinths. The "arena " together with the stables attest the great passion of count Bolasco for horses. Statues, horses, and the tower are the remains of the disappeared Cornèr "Paradise garden".

The Park now boasts over 1,000 trees of 65 different species, out of which 35 are between 75 and 125 years old, as well as 440 plants ranging from 50 to 70 years old. 
In 1967 the last descendant of Revedin-Bolasco family, the countess Renata Mazza, donated the Villa and the Park to the University of Padova, which managed the area jointly with the municipality of Castelfranco till 2014.

According to the abovementioned restoration project, in 2013 the Park was completely renovated while the Villa underwent to some restoring works on the ground floor of the winter and summer wings (see Figure 1), which now hosts a Regional Centre of the University for restoration of historical parks and monumental plants, so as conferences and meetings in the frescoed dance hall.

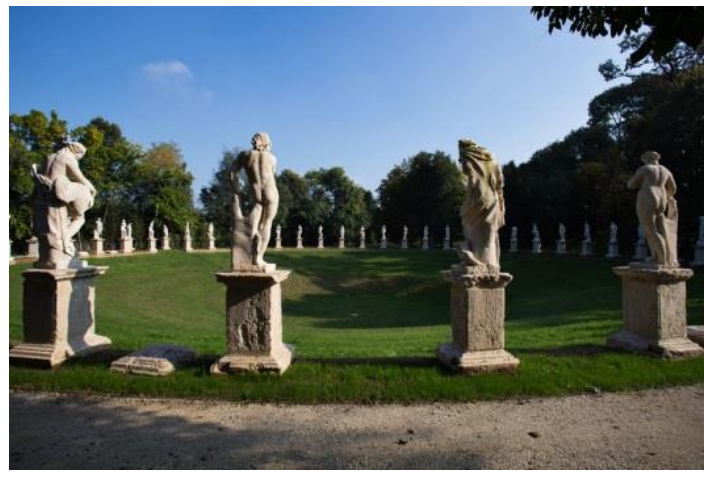

Figure 6: View of the arena-cavallerizza

\section{DATA ACQUISITION}

In 2012 our Research Center of Geomatics was charged by the University of Padova to carry out a survey of the whole site, Villa and Park, as preliminary step for subsequent restoration and rehabilitation works. Given the complexity of this commitment, here we will report only about the measurement and data processing activities undertaken in relation to the Villa.

The workflow adopted for the survey of the inner and outer parts of the building and for the data processing is summarized in figure 7 .

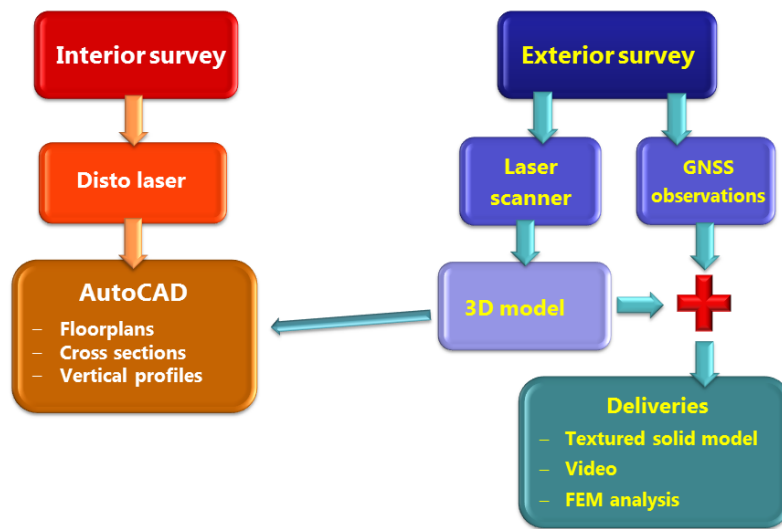

Figure 7: Workflow adopetd for data acquisition and processing

\subsection{The survey of the Villa}

In order to meet the technical specifications provided by the University, we adopted different approaches to survey the interior and exterior of the building. The geometry of all 160 rooms was captured with two Leica Disto D3a BT hand-held laser meters (Figure 8a). A redundant set of angle and distance measurements were collected in each room setting a $1 \mathrm{~m}$ height from the pavement as common reference to get homogeneous data. The outer walls of the Villa were instead surveyed with a Leica C10 and a Faro Focus 3D 120 terrestrial laser scanners (Figures $8 \mathrm{~b}, 8 \mathrm{c}$ ). The former, a pulsed laser ranging sensor, was employed to measure 4 closed traverses around and through the building structure. From each laser station we acquired a set of scans with an average spatial resolution of about $1 \mathrm{~cm}$. Following a few initial tests, we deemed this value the most appropriated for the extraction of plans, profiles and elevations from the 3D model. Furthermore, a side overlap of 30\%-50\% was set between adjacent scans. Considering the quite regular geometry of the building, this degree of overlap was deemed enough to ensure a successfull registration of the scans. Positions of the traverse vertices were measured by the $\mathrm{C} 10$ laser scanner using specific Leica target poles (Figure 9).

The Faro Focus 3D, a phase-based laser scanner, was instead employed to acquire very high resolution point clouds of a few monumental rooms (e.g. stables, dance hall,etc.) and the exterior of the south courtyard.

A comparison between the quality (measurement noise and level of detail) of Faro Focus 3D and the Leica C10 scans is shown in figure 10 .

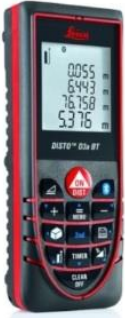

(a)

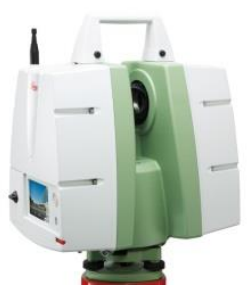

(b)

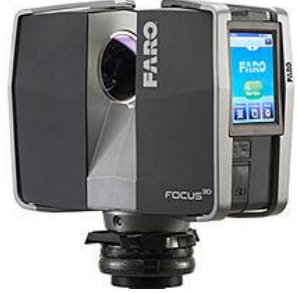

(c)
Figure 8: Leica Disto D3a BT hand-held laser meter (a); Leica C10 (b) and Faro Focus 3D 120 (c) terrestrial laser scanners.

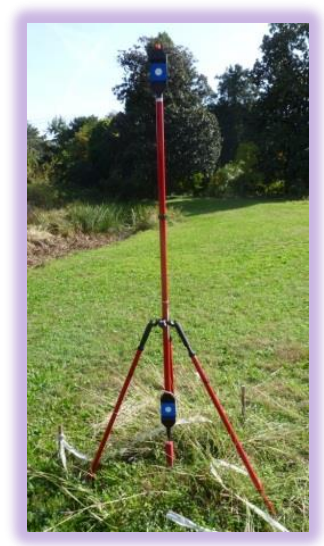

Figure 9: Leica target pole used for traversing with the C10

As required by the thecnical specifications, the resulting 3D model had to be georeferenced in the national reference frame (Gauss-Boaga). To this aim we measured the coordinates of 6 Ground Control Points (GCPs) with two geodetic GNSS receivers (Topcon Hiper II). The observations were performed simultaneously to laser traversing in order to determine the GCPs coordinates in the local reference frame of the laser 3D model as well. Some of these points were set in place of the targets used for traversing while others were located on different positions. 
The spatial distribution of measured traverses and GCPs is shown in figure 11.

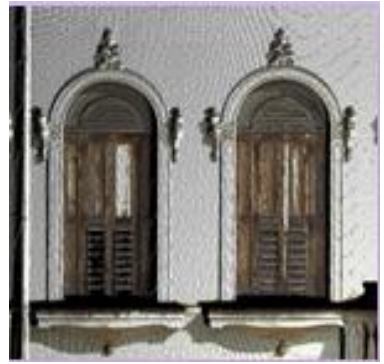

(a)

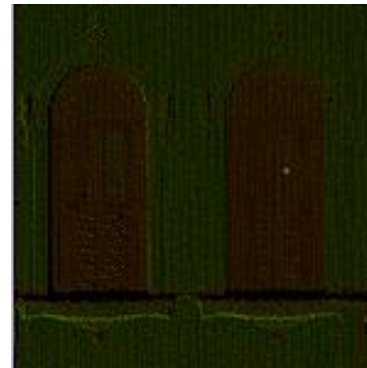

(b)
Figure 10: Detail of a Faro 120 (a) and of Leica C10 (b) scan on the same portion of an outer wall of the Villa. C10 laser points colored according to an intensity-based false color scale.

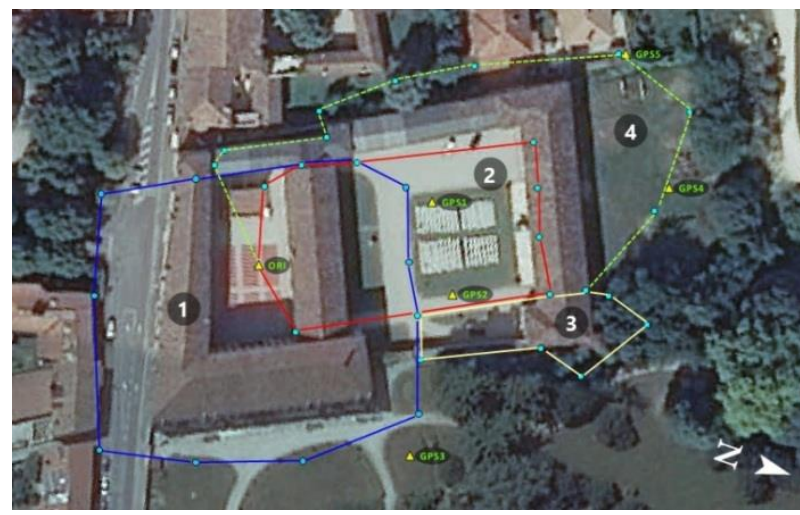

Figure 11: Spatial distribution of the 4 traverses and GCPs

\section{DATA PROCESSING}

The data collected with the laser distance meters were then processed in AutoCAD in order to reconstruct the 2D geometry of the levels of the Villa and to produce the corresponding plans. Firstly a vector model of each room was separately reconstructed from the Disto measurements. Then, in order to correclty recover the spatial distribution of the rooms, we exploited the geometric information provided by the laser 3D model of the outer walls (see the schema in figure 7). Namely, horizontal and vertical cross sections were extracted from the global point cloud and used as a spatial reference to support the operator in reassembling in a unique geometrically correct dataset the vector models of each room. Similarly, additional cross sections of the $3 \mathrm{D}$ model were employed to produce the requested inner profiles and vertical elevations of the Villa at the 1:50 and 1:100 nominal scales.

Examples of produced floorplans and elevation profiles are presented in figures 12 and 13.

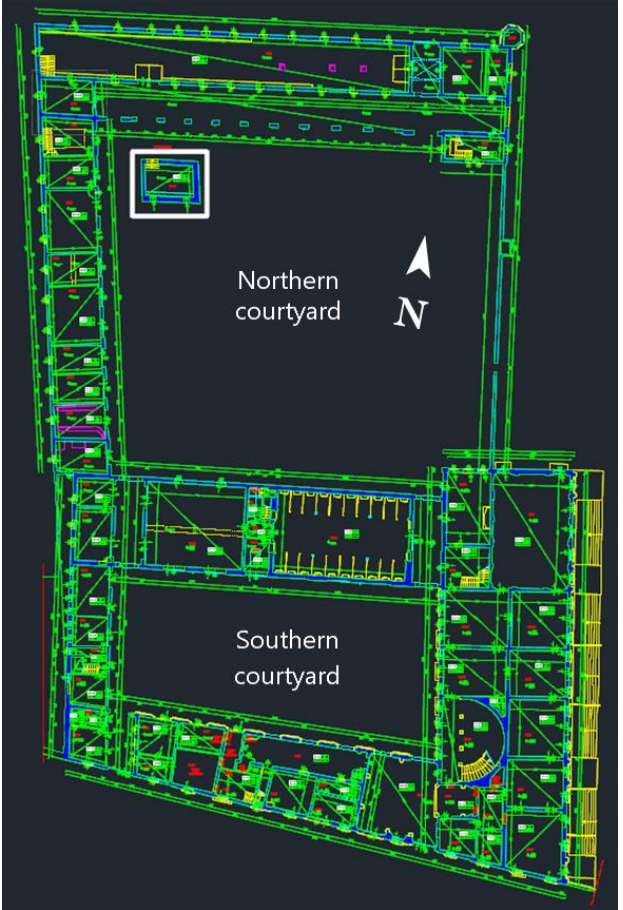

Figure 12: Floor plan of the ground level

The data acquired with the $\mathrm{C} 10$ were processed in Leica Cyclone software. At first each scan was carefully filtered in order to remove unwanted objects like vegetation, nearby buildings, vehicles and others unnecessary elements. Then each traverse was rebuilt and adjusted, generating in this way groups of prealigned scans. Each pre-alignment was furtherly refined with Cyclone built-in variant of the well known ICP algorithm (Besl and McKay, 1992). With this approach, traversing enabled us to add further constraints into the registration step, and thus to strength the alignment among the scans. The ICP was then reapplied to merge together the grouped scans in a global point cloud. In this step matching points were manually selected by the operator, as no a priori information about spatial relationships between the datasets were available (each C10 scan group was defined in a different local reference frame, setup with the corresponding traverse). The same procedure was applied in order to add to the global model the point clouds acquired with the Faro 120 laser scanner. At the end of this processing stage, the constraints provided by the traverses and the degree of overlap among the various scans, allowed us to produce a very geometrically accurate global 3D model.

The Faro laser scanner was also used to survey a few rooms of the ground level of particular architectural interest. From generated dense DSMs (DDSM) we extracted a set of orthophotos with Bentley Pointools software.

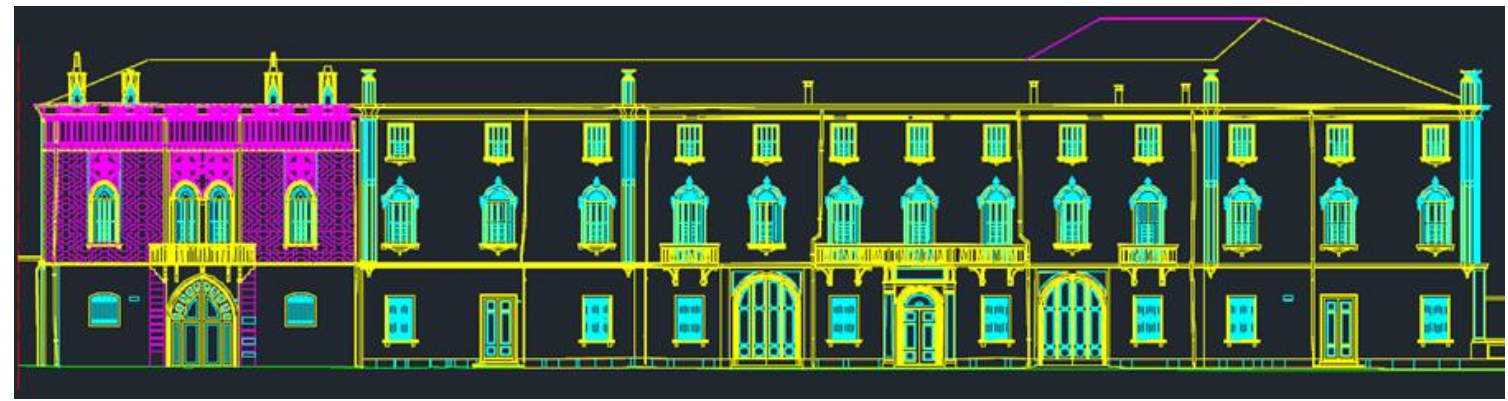

Figure 13: Elevation plan of the winter wing façade (south side) 
As regards the scan georeferencing, acquired fast-static GNSS data were post-processed in TopconTools software. Doubledifferencing these observations with reference measurements collected by a nearby $(500 \mathrm{~m})$ permanent station $(\mathrm{CAFV})$ of the Leica GNSS national Network ItalPos (Leica Smartnet, 2017) allowed us to calculate GCPs coordinates with residual errors at millimeter level (Figure 14). Next, the WGS84 coordinates of the GCPs were properly projected in the national grid using officially tabulated transformation parameters.

These coordinates were then imported in Cyclone software and used to georeference the global laser point cloud through a registration procedure based on automatic target recognition. At the end of this data processing step we obtained a 3D model consisting of about 208.000 .000 of points with an average spatial resolution of $1 \mathrm{~cm}$. A view of the resulting model, rendered in a false color scale according to laser intensity, is shown in Figure 15 .

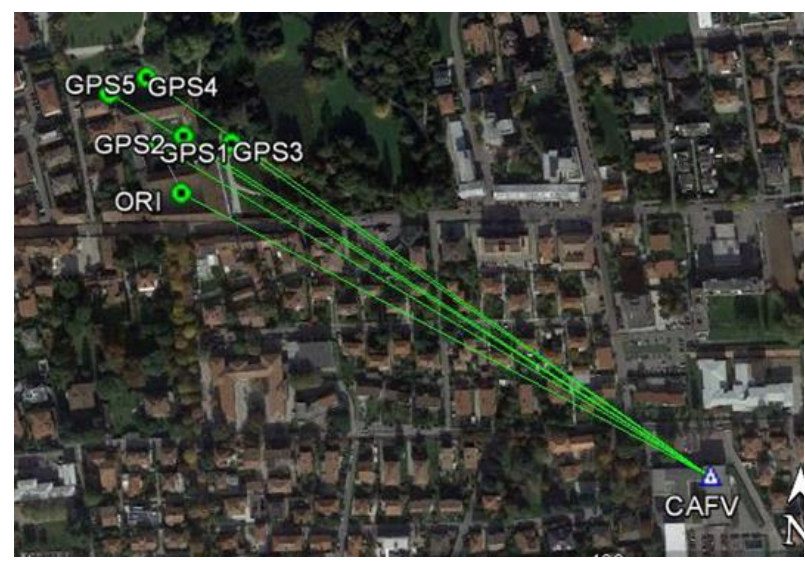

Figure 14: Baselines between observed GCPs and the local permanent station of the Leica ITALPOS GNSS network

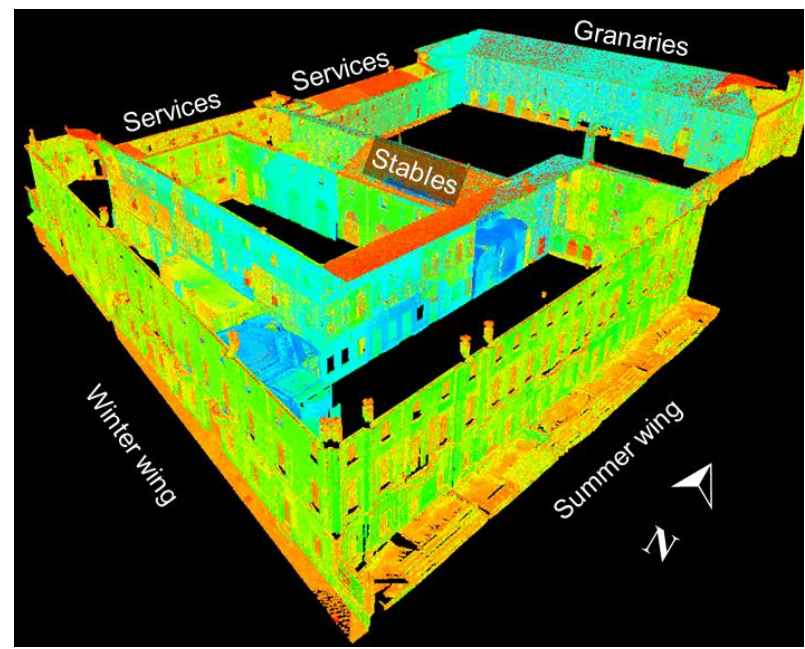

Figure 15: View of the global point cloud of the Villa

\section{SOLID MODELING}

In this section we illustrate the procedure adopted to create a solid model of the whole building of Villa Revedin-Bolasco in Rhinoceros software. This model could be employed as a basic dataset in BIM (Building Information Modeling) application aimed at the documentation, conservation and restoration of the Villa. In order to simplify this activities, it is essential to have reliable and informative spatial data. The current state-of-the-art approach to collecting, organising and integrating survey data of an existing building into a single data structure is to model it using BIM tools (Eastman, 2008). BIM represents the process of development and use of a computer generated model to simulate the planning, design, construction and operation of a building. The resulting model, a building information model, is a data-rich, object-oriented, intelligent and parametric digital representation of the building, from which views and data appropriate to various users' needs can be extracted and analysed to generate information that can be used to make decisions and to improve the process of delivering the building (Azhar, 2011). Nowadays, BIM technology allows to use in integrated way in the same environment advanced parametric modelling tools, functional intelligence, and object attributes. Furthermore, BIM technology enables different operators to work on the same object exploiting new interoperability standards: the different operators involved in the project can update and modify the BIM model according to their needs. Then, effect of the changes can be immediately evaluated by other users (Barazzetti et al., 2015).

Due to the limited capabilites of Rhino for managing very large datasets, the global point cloud was decimated using octree filtering technique. The laser model was therefore reduced of $40 \%$ from original 208 millions of points and then decomposed in several parts which were separately imported in Rhino and here re-assembled. This approach allowed us to avoid computational overload within the solid modeling stage while still keeping an adequate level of detail. Walls, columns, windows and other remarkable archite-ctural elements were reconstructed as solid objects from the imported point clouds by repeatedly applying plane fitting tools or by replacing complex shapes with a combination of more simple solid geometries (e.g. cones, spheres, cylinders, etc.). Dimensions of reconstucted object were derived from the 3D laser point cloud. For example, walls and columns were modeled with basic solid geometries according to the corresponding values of height and thickness measured on the 3D model (Figure 16). Similarly, the balaustrades of the several balconies, that decorate the winter and summer wings of the Villa, were approximated with more simplified solid forms as illustrated in figure 17.

A global view of the resulting solid model of the whole Villa is shown in figure 18.

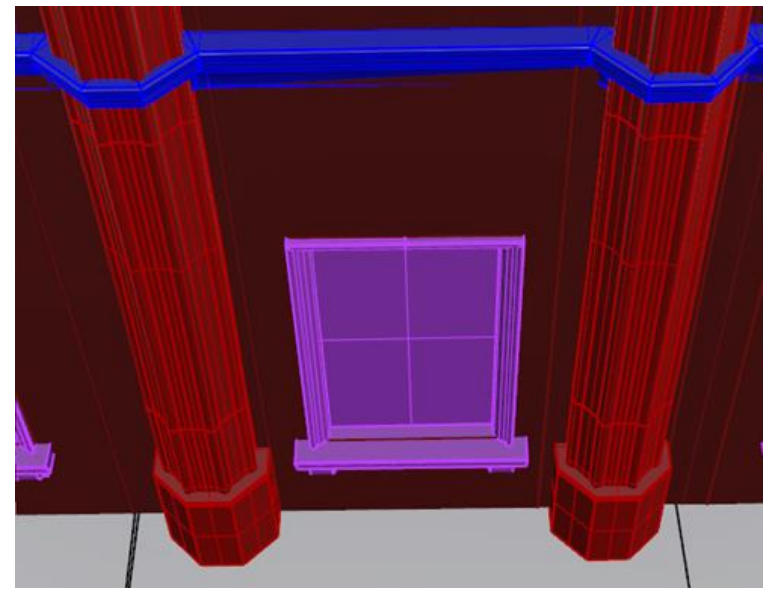

Figure 16: Detail of the solid modeling of columns and windows of the Villa 

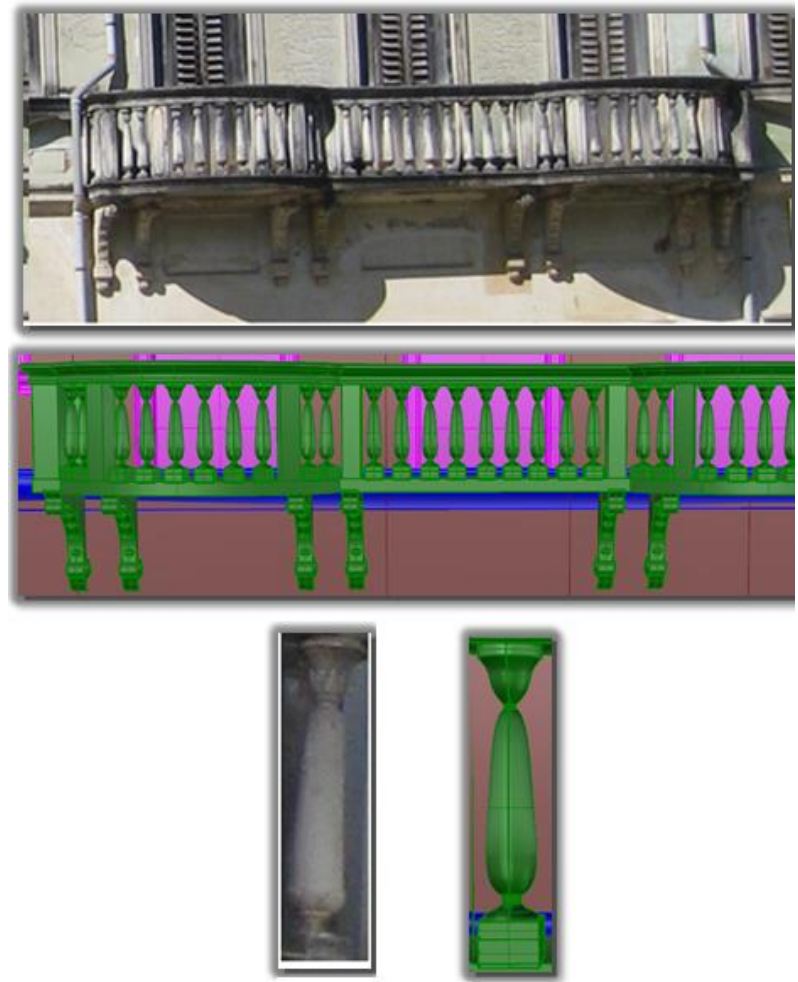

Figure 17: Modeling of balaustrade elements with simplified solid geometries

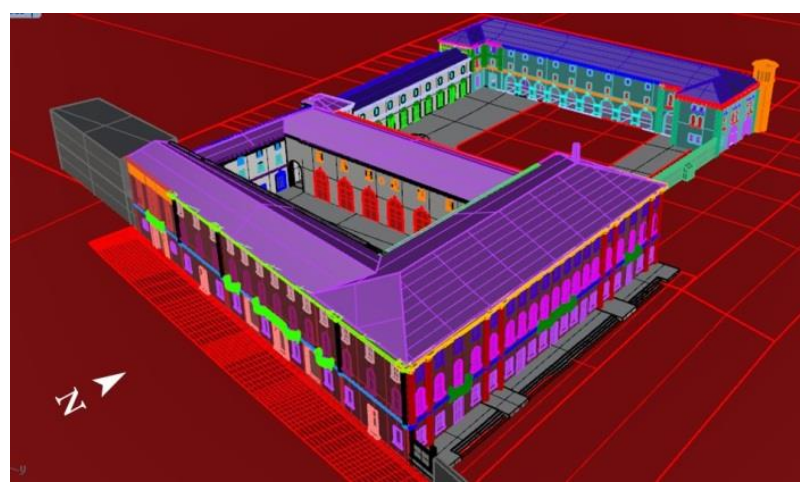

Figure 18: The solid model of the whole Villa RevedinBolasco generated in Rhino software

\section{FINITE ELEMENT ANALYSIS (FEA)}

The survey of the Villa carried out with the terrestrial laser scanners enabled us to reconstruct the exact geometry of the building, offering the basis for performing structural analysis supported by a realistic model, useful also in the design of repair interventions. In this regard, the solid model generated in Rhino software was then used to carry out a Finite Element Analysis (FEA).

The advantage of the use of a laser scanner-based 3D model for structural analysis investigations is mainly represented by the availability of a highly detailed representation of the object's geometry, which allows for a better estimate of the stressing states. Tipically, structural investigation tools can be related to the following two main groups: traditional static analysis and Finite Element Analysis (FEA). The latter seems to be more suited for complex structures, as it provides several advantages, among which we recall the option to work in a $3 \mathrm{D}$ space, to perform different kind of analysis (linear, non-linear, dynamic, etc.) and to test specific features of the structure with a stepwise approach. On the other hand FEA doesn't allow to estimate the plausible response in the case of elements that are non-stressing resistant. The interest for applying structural analysis to an historical building relies in that FEA can help in defining the eventual state of danger and in forecasting the future behavior of the structure.

This kind of analysis essentially involves modeling the structure by dividing the body in small elements (such as triangular elements) with definite mathematic models. These finite elements are joined with the nodes, which are corners of elements. In FEA, the geometry of structure is idealized as one dimensional by considering the structure to be made of linear elements, twodimensional elements, or three-dimensional elements as solid depending on the problem of structure body. Analysis by finite elements methods depends on stress evaluation of the nodes. The more elements are used, the better approximation can be obtained. However, this relationship makes the problem more complex and increases the processing time. For appropriate and rational analysis, the definition of the mechanical properties of the material and the implementation of constitutive laws for decayed materials is needed. However, the analysis of historical constructions is a complex task for building material that is not homogeneous isotropic and linear elastic.

Given the actual size and geometrical complexity of the solid model only a small portion of the building was employed for the FEA, namely the one showing at visual inspection major stability issues.

A few cross-sections extracted from the 3D solid model of the wall were imported as DXF in the Straus software, considering a $40 \mathrm{~cm}$ section depth, subdivided according to a series of 4-node elements (Plate) of $10 \mathrm{~cm}$ each. A linear static analysis was performed on such cross-sections, aimed to study the response of the wall structure to the different effects of the weight and the off-plumb line.

In Straus, all the plates were assigned the same physicalmechanical properties, i.e. continuous and homogenous stonework structure featuring a 40-cm thickness for building structure. Regarding the model's degree of freedom (DOF), the structure has been considered fixed to the ground by removing all the DOFs of the nodes (triangle vertices) placed at the bottom of the model. A force of $250 \mathrm{~N} / \mathrm{mq}$, acting along the $\mathrm{Z}$ axis (vertical), was then applied to each plate of the $3 \mathrm{D}$ model shingle in order to simulate the effect of snow accidental weight (green arrows).

According to Italian regulations and to the assigned load, two different kinds of analysis were carried out:

1. Static analysis, from which charts for stress plate for plate moments have been derived. This analysis is performed by Straus through following steps: model linear static analysis, model linear buckling analysis, nonlinear static analysis, and consideration of the structure's own weight and snow accidental weight.

2. Dynamic analysis, by simulating the effects on the structure due to an earthquake and considering the structure's own weight, snow accidental weight, and wind effect.

Some results of the application of finite element analysis to a small portin of an outer wall of the Villa are shown in figures 19 and 20. 

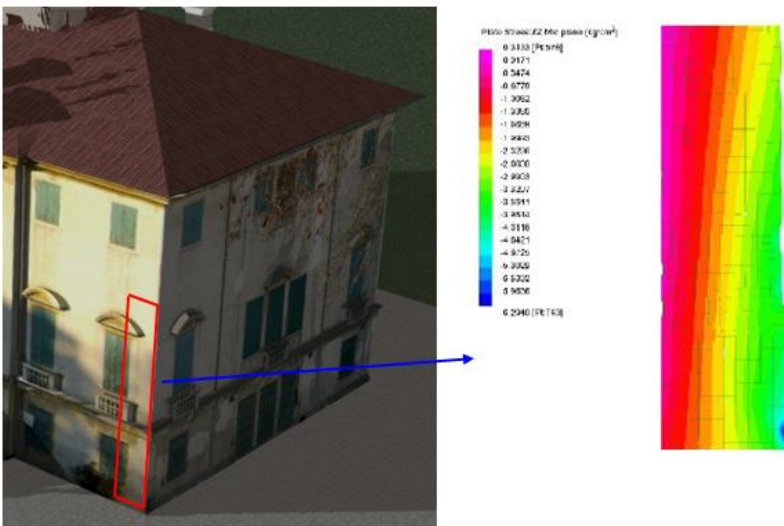

Figure 19: Results of the stressing effect of the wall weight

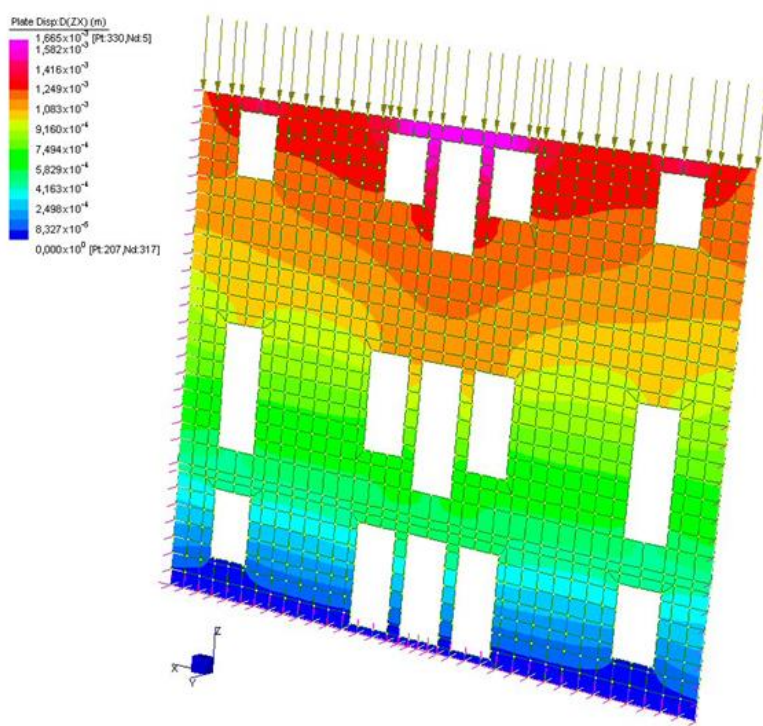

Figure 20: Analysis of deformations due to the roof weight

\section{CONCLUSIONS}

In this paper we have presented all the steps and challenges addressed and solutions adopted concerning the survey, solid modeling and FEA from terrestrial laser scanning data of the historical complex of Villa Revedin-Bolasco. The work was undertaken by CIRGEO within the framework of a restoration project promoted by the University of Padova, in conjunction with the municipality of Castelfranco, and supported by the Regione Veneto through european funds.

The Villa was surveyed using different measuring sensors, such as Disto laser meters, for the interiors, and terrestrial laser scanners for the outer walls. In particular, the Leica C10 laser scanner demonstrated to be very useful in this context given its capability to performe traverses. Indeed, by traversing, additonal constraints could be introduced in the scan alignment step. These constraints, along with an overlap of 30\%-50\% between adjacent scans, ensured to generate a very accurate 3D laser model. However, the high level of detail provided by this model could not fully exploited for creating a solid modeling of the Villa. To overcome computational issues at this step, a decimated version of the global point cloud had to be employed. In addition, a small portion of the solid model was then used to perform a Finite Element Analysis in order to evaluate effects of outer walls and roof weight on the structure itself.
In this regard, achieved results demonstrate that point clouds can play a fundamental role in structural simulation of existing constructions, especially in the case complex historical structures.

\section{REFERENCES}

Azhar, H. S., 2011. Building information modeling (BIM): benefits, risks and challenges [online], McWhorter School of Building Science, Auburn. Available from Internet: http://ascpro.ascweb.org/chair/paper/CPGT182002008.

Barazzetti, L., Banfi, F., Brumana, R., Gusmeroli, G., Oreni, D., Previtali, M., Roncoroni, F., and Schiantarelli, G., 2015. BIM From Laser Clouds And Finite Element Analysis: Combining Structural Analysis And Geometric Complexity. The International Archives of the Photogrammetry, Remote Sensing and Spatial Information Sciences, XL-5/W4, 345-350, doi:10.5194/isprsarchives-XL-5-W4-345-2015, 2015.

Barber, D., Mills, J., Bryan P. G., 2001. Laser Scanning and Photogrammetry-21th Century Metrology. Proc. of CIPA 2001 Int. Symposium "Surveying and Documentation of Historic Buildings, Monument”, Potsdam, Germany.

Besl, P.J., McKay, N.D., 1992. A Method for Registration of 3D Shapes. IEEE Transactions on PAMI, vol. 14, no. 2, pp 239-256.

Beraldin, J.-A., Picard, M., El-Hakim, S., Godin, G., Borgeat, L., Blais, F., Paquet, E., Rioux, M., Valzano, V., Bandiera, A., 2005. Virtual Reconstruction of Heritage Sites: Opportunities and Challenges Created by 3D Technologies. Proc. of the International Workshop on "Recording, Modeling and Visualization of Cultural Heritage”, Ascona, Switzerland.

Eastman, T. S. L. 2008. BIM handbook: a guide to building information modeling for owners, managers, architects, engineers, contractors and fabricators. Hoboken, NJ: John Wiley and Sons, Ltd. 504 p.

Guarnieri, A., Remondino, F., Vettore, A., 2004 Photogrammetry and Ground-based Laser Scanning: Assessment of Metric Accuracy of the 3D Model of Pozzoveggiani Church. Proc. of FIG Working week 2004, "The Olympic Spirit in Surveying", Athens, Greece.

Leica Smartnet, ItalPos (Italian Positioning Service) http://smartnet.leica-geosystems.it/SpiderWeb/frmIndex.aspx, (01 April 2017)

Remondino, F., Girardi, S., Gonzo, L., Rizzi, A., 2008. Multiresolution modeling of complex and detailed Cultural Heritage. Proc. of $9^{\text {th }}$ Int. Symposium on Virtual Reality, Archaeology and Cultural Heritage (VAST 2008), pp. 1-8, Braga, Portugal. 